\title{
CALDERÓN TRADUCIDO AL PORTUGUÉS (SIGLO XVIII)
}

I. Cuando en 1640 termina la hegemonía política de España sobre Portugal, la difusión de autores españoles, en libro y en los patios de comedias, así como el cultivo del castellano por autores portugueses, continúa alrededor de un siglo más. Todavía en 1761 salen de las prensas portuguesas obras de autores portugueses escritas en castellano. Todavía en la cuarta década del siglo xvirI actúa con éxito en el Teatro do Bairro Alto de Lisboa, una compañía española.

Sin embargo, las cosas han cambiado mucho en este terreno desde el siglo XVII al XVIII, y cambian todavía más, y rápidamente, según avanza este siglo. Por una parte, está la aparición de nuevas influencias literarias que, a través de abundantes traducciones, vienen a suplir, al menos en ciertas capas de la sociedad portuguesa, la influencia española, dormida en sus laureles. En el teatro: la tragedia clasicista, Molière y, sobre todo, la ópera italiana y Apostolo Zeno, Metastasio y Goldoni. Por otra parte, el obstáculo linguístico: el castellano, no sólo deja de cultivarse por los poetas, sino que acaba por no ser entendido por el pueblo. Es entonces cuando se impone la tarea de traducir a los autores españoles, cosa que rara vez había sucedido en épocas anteriores, aunque hay que aclarar que el lector culto no necesitaba de traducciones, leía perfectamente el español. Esto puede explicar que los únicos novelistas españoles traducidos al portugués en el siglo xvirI sean Cervantes y Mateo Alemán, y que, salvo La española inglesa, cuya primera traducción 
se publica en 1748, el Quijote y el Guzmán de Alfarache no aparezcan hasta 1794 y 1799, respectivamente ${ }^{1}$.

En cuanto al teatro, las circunstancias son diferentes, y se comprende. Dejemos a un lado el teatro cortesano, con su público aristocrático, aparentemente atraído por la tragedia clasicista y los últimos falsos destellos de los epígonos portugueses de Calderón, y, sin duda, cada vez más aficionado a los espectáculos musicales. Otra cosa es el teatro público, al que tiene acceso una masa indiscriminada de espectadores, probablemente con predominio del pueblo abatido, que ya no entiende más lengua que la portuguesa y que exige espectáculos de acción, cómicos o sentimentales, y, con frecuencia, caracterizados por su plebeyez. Es en ese momento, al trasponer más o menos las lindes del medio siglo, cuando comienzan a traducirse comedias españolas - dejo ahora las de otros países-, adaptadas al gusto de ese público, vulgarizándolas, en el peor sentido de la palabra, traicionando el original y cargando la mano de gracias burdas y chocarreras. Complemento de esta labor es la proliferación de entremeses, donde abunda la tosquedad y la grosería, y que, a juzgar por su número, se diría que hacen sombra a las comedias en las preferencias de aquel público.

Este teatro, tenazmente mal llamado "teatro de cordel», como si se tratara de un género dramático específico, tenía, después de su presentación al público en los teatros lisboetas del Bairro Alto, del Salitre y de la rua dos Condes, una nueva vida gracias a las impresiones sueltas, éstas sí pliegos de cordel, que vendían a precio módico, a la vez que romances e historias diversas, libreros y ciegos ambulantes. Si nos atenemos a las fechas, cuando se dan, de las ediciones de comedias, que no deben ir mucho más allá de la fecha de su representación en los teatros, comprobamos, una vez más, lo tardío de la traducción de textos españoles, pues casi todas pertenecen al último tercio del siglo Xvirr. En su mayor parte, se publicaron anónimas, pero desde el siglo pasado se viene atribuyendo erróneamente la autoría de muchas de ellas a Nicolau Luiz, autor dramático y empresario teatral en la Lisboa de aquellos años, o, lo que es más probable, la responsabilidad, iy qué responsabilidad!, de las traducciones y adaptaciones al gusto portugués 2

1 Véase A. GONÇALVES RODRIgUES, A novelística estrangeira em versão portuguesa no periodo pré-romântico, Coimbra, 1951.

2 Para Nicolau Luiz, véase: J. M.` DA Costa e Silva, Ensaio Biográphico-Crítico sobre os melhores Poetas Portuguezes, X, Lisboa, 1855, págs. 294327; InocEncio Prancisco da Silva, Dicionário Bibliográphico Portuguez, VI y XVII; Tzofilo Braga, his. tória do Theatro Portuguez. III. A Baixa Comédia e a Opera, Porto, 1871, y Luctana Stegagno Picchio, Historia do Teatro Português, Lisboa, 1969. 
¿Qué autores españoles son los preferidos para esta tarea? No Lope de Vega, quizá considerado pasado de moda; todo lo más, de su grupo, alguna obra de resonancia lusitana, como Reinar después de morir, de Vélez de Guevara. Los autores predilectos en aquel momento son Calderón de la Barca y alguno de los representantes, no siempre los mejores, de su ciclo, como Agustín Moreto, Antonio de Solís, Matos Fragoso y Bances Candamo, entre los que he conseguido identificar hasta ahora. Y las comedias de Calderón identificadas: El príncipe constante, Afectos de odio y amor, El alcalde de Zalamea, Nadie fie su secreto y El alcalde de sí mismo ${ }^{3}$. Excepto el caso de El príncipe constante, por sus vinculaciones con la historia de Portugal, se me escapan las razones que llevaron al traductor, o traductores, a elegir estas comedias de entre el amplio repertorio calderoniano, aunque sí puede explicarse la elección de El alcalde de Zalamea por su fuerza dramática y el carácter popular del conflicto en él planteado. Es justamente de este drama y de $E l$ príncipe constante de los que voy a tratar a continuación 4 .

II. Nunca mejor empleado que en este caso el aforismo italiano «traduttore, traditore». Sin embargo, con tratarse de dos ejemplos de traducción peregrinos, la de $E l$ príncipe constante 5 es la que menos traiciona al original. El traductor sigue el texto de Calderón con bastante respeto en todo lo que se refiere al drama personal de D. Fernando y a sus relaciones con el resto de los personajes; pero se permite grandes libertades con algunos de esos personajes, suprimiéndolos o cambiando sus sentimientos o el nombre o la categoría social. Altera el orden de las escenas e inventa otras ${ }^{6}$, y divide los actos en escenas que se corresponden con el cambio de lugar, indicado en todos los casos, excepto en uno: acto I, jardín; sala; jardín con mar al fondo; II, jardín; salón de trono; III, prisión; bosque con mar y naves; mar y murallas. Unas veces abrevia, otras amplifica, y frecuentemente empo-

3 Debo indicar que alguno de estos autores y obras ya habian sido sefialados por Téfilo Braga, ob. cit., y Albino Forjaz de Sampaio, Subsidios para a História do Teatro Português. Teatro de Cordel, Lisboa, 1922.

4 Los textos originales de estas dos obras ya habian sido publicados en Portugal en el siglo XVII: El principe constante, en Comedias de los mejores y mas insignes Ingenios de España, Lisboa, 1652, y El alcalde de Zalamea, con su primitivo título El garrote más bien dado, en Doce comedias las más grandiosas que hasta ahora han salido de los mejores y más insignes Poetas, Lisboa, 1653.

5 Comedia nova intitulada $O$ heroico luzitano. Principe constante, e martyr. Al final: «Na Of. de Antonio Gomes. Com lic. da R. M. da Com. Ger. s. o Ex. e C. dos L.», 40 págs. a dos columnas.

6 Esto da lugar a un aumento-de versos en la versión portuguesa: 3162 frente a los 2796 del original español.

LXIII, $1.0-2.0-7$ 
brece la calidad poética del texto, aligerándolo de imágenes y metáforas.

Por otra parte, la impresión del texto es pésima. Si juzgamos al impresor, António Gomes, de Lisboa, por esta edición y otras suyas que he visto, habrá que calificarlo de chapucero. Quizá los descuidos se deban a la condición popular de esta clase de publicaciones; sea como sea, abundan las erratas, hay rimas caóticas, saltos de versos o atribución de los de un personaje a otro. En fin, un texto estragado, con errores tan abultados, que, al menos todos, no parece posible atribuirlos al más torpe de los traductores.

Antes de entrar en el análisis del texto portugués y compararlo con el español, veamos qué ocurre con los personajes que intervienen en el drama. En el original ${ }^{7}$ son los siguientes: Don Fernando, Don Enrique, Don Juan, Rey moro, Muley, Fénix, Rosa, Zara, Estrella, Tarudante, Don Alfonso, Celín, Brito, cautivos, soldados y moros. En la traducción: D. Affonso, Rey de Portugal; D. Henrique, irmão de; D. Fernando, Infante de Portugal; D. João, fidalgo portuguez; ElRey de Fez; Fénis, sua filha; Zara, sua prima; Turcalina, creada de Fénis; Tarudante, Príncipe de Marrocos; Lourenço, graciozo portuguez; Celim, mouro; Muley, mouro; hum Capitão que falla; soldados portuguezes, mouros e captivos. Hay, en general, coincidencia entre las dos listas, pero con ciertas modi. ficaciones que señalo a continuación.

Brito, que es un gracioso moderado, con muy escasa intervención en el original ${ }^{8}$, cambia de nombre en la versión portuguesa, Lourenço, y tiene una intervención más extensa e inmoderada, totalmente desplazada del contexto dramático en que se inscribe. Si en ambos casos se trata de un soldado cobarde, el portugués es además fanfarrón y presume de «fidalguia». Sin asidero femenino en el drama de Calderón, el anónimo portugués le asigna como pareja a Turcalina, criada y graciosa, con quien retoza e intercambia constantemente frases vulgares. El adaptador ha reunido en Turcalina, personaje de su invención, a las tres damas que Calderón pone al servicio de la Princesa: Rosa, Estrella y Zara, y ya veremos la transformación que sufre ésta. Pero mientras estas moras son delicadas, bellas y comedidas, como conviene a servidoras de tan alto personaje, Turcalina es la versión femenina del gracioso en su aspecto más burdo y grosero, buena pareja para Lourenço. A cargo de los dos corren varias escenas a manera de dúo entremesil, que no se

7 Como texto de referencia, utilizo la edición de la Primera Parte de Comedias de Pedro Calderón de la Barca, ed. de A. Valbuena Briones, I, Madrid, C. S. I. C., 1974, págs. 363-448.

838 versos en la jornada primera y 8 en la tercera; en la segunda no aparece. 
distinguen precisamente por su ingenio y aticismo, distribuidas en los tres actos - dos en el 1..$^{\circ}$; una en el $2 .^{\circ}$, y dos en el $3 .^{\circ}-$, aparte, claro está, de sus intervenciones cerca de otros personajes.

Zara se ha transformado en prima de Fénix y en su rival amorosa, puesto que también ella suspira por el apuesto Muley, complicándose así la acción secundaria a cargo de esta pareja de enamorados. El resto viene a continuación.

Calderón comienza la primera jornada con un grupo de cautivos cristianos que cantan, a petición de Zara, para solaz de Fénix, a quien su padre, Rey de Fez, le da el retrato de Tarudante, que le ha elegido para esposo. Disgusto de Fénix, enamorado de Muley, quien lo está también de ella. Muley llega precisamente en ese momento para dar cuenta al Rey del encuentro habido con naves portuguesas que se dirigen a sitiar Tánger. En otra escena, salen los Infantes Fernando y Enrique, que acaban de desembarcar en la costa marroquí. En combate, Muley cae prisionero de D. Fernando, pero es puesto en libertad al contarle sus desdichados amores. Sin embargo, las tornas se vuelven, y en otro combate son los Infantes quienes caen prisioneros del Rey de Fez. D. Enrique queda en libertad para que regrese a Portugal y proponga al Rey D. Duarte, hermano de los Infantes, el rescate de Fernando a cambio de Ceuta. Aquí termina la jornada.

¿Qué hace el traductor? En primer lugar, hay que tener en cuenta que al iniciarse la acción en la versión portuguesa, D. Fernando hace ya algún tiempo que es prisionero del Rey de Fez. Por otra parte, no olvidemos que Zara es prima de Fénix y Turcalina servidora de ésta. En cuanto al resto, el comienzo es, salvo ligeras variantes, el mismo del original. El diálogo que mantienen padre e hija con motivo del anunciado matrimonio es más extenso en la traducción: los cinco entrecortados versos en que Fénix expresa, en la obra de Calderón, su disgusto por la decisión paterna, se transforman en 107 tensos versos que merecen una larga y airada respuesta del Rey. En este momento, Zara, que ama secretamente a Muley, se entera de que también lo ama su prima. Como, por decisión del traductor, la batalla en que caen prisioneros los portugueses ya ha tenido lugar, no es necesaria la fatigosa relación de Muley explicando el encuentro naval. En cuanto al diálogo entre Fénix y Muley, con los celos de éste al ver el retrato de Tarudante en manos de la Princesa, tiene como variante más acusada, aparte los comentarios impertinentes de Turcalina, un final con aparente ruptura entre los enamorados: 
FÉn. Oh funesto sentimento!, e não queres atender-me?

Mul. Depois, cruel, de perder-me não te escuto hum só momento.

Fén. Tu a meus doces afagos me das esta recompença?

Mul. Pois se a julgas por offença, ficamos os dois bem pagos.

Tur. Bem pagos e bem repagos.

FÉn. E quem vio maior rigor?

Mul. Quem vio maior dezamor?

FÉn. De seus olhos fugir quero.

Mul. Que o não vella espero.

TUR. Estão asnos de primor.

Mul. Fica, ingrata.

FÉN. Vai-te infiel.

Mul. Não te recordes de mim.

FÉN. Teus amores ténhão fím.

Os Dous. Oh pensamento cruel!

TUR. Gostoso sarapatel.

FÉn. Não serás de mim lembrado.

Mul. Não terei de ti cuidado.

Os Dous. Pois neste fatal instante acabou hum peito amante entre hum desprezo abrazado.

(I, pág. 7, col. a) 9

D. Fernando y D. Juan esperan el regreso de D. Enrique con el rescate. Zara declara su amor a Muley, que la deja con la palabra en la boca, alegando que desde su desengaño con Fénix ya no cree en el amor. Todo esto es nuevo con respecto al original. Lo es también lo que sigue, al menos por su ubicación, puesto que buena parte de la jornada segunda, texto español, pasa a engrosar este primer acto: sueño présago de Fénix, reproches mutuos en un nuevo diálogo con Muley; regreso del Infante D. Enrique con el anuncio de la muerte de D. Duarte y cómo dejó ordenado en su testamento que se entregase Ceuta a cambio de D. Fernando, lo cual dispone también el nuevo monarca, D. Alfonso. El Infante rechaza con vehemencia el cambio; el Rey de Fez, furioso, lo amenaza con la condición de esclavo. Calderón termina esta escena con una doble promesa: la de D. Enrique, que regresa a Portugal, de volver a liberar a su hermano, y a la de Muley, de salvarlo en pago de la vida que le debe. El

9 Reproduzco los textos sin más modificaciones que salvar erratas, normalizar el uso de mayúsculas y de guión entre verbo y pronombre personal átono, y modernizar acentos y puntuación. 
adaptador suprime esto y termina el acto con palabras de D. Fernando deseando que se apresure su muerte.

Si estas escenas han pasado al primer acto portugués, ¿qué queda para el segundo? El traductor lo comienza con todo el material calderoniano que restaba de la segunda jornada: escena del jardín, Fénix manda que le llenen de flores un canastillo, se lo presenta el Infante, y en el diálogo entre los dos, recitan sendos sonetos; en la traducción queda sólo el de D. Fernando:

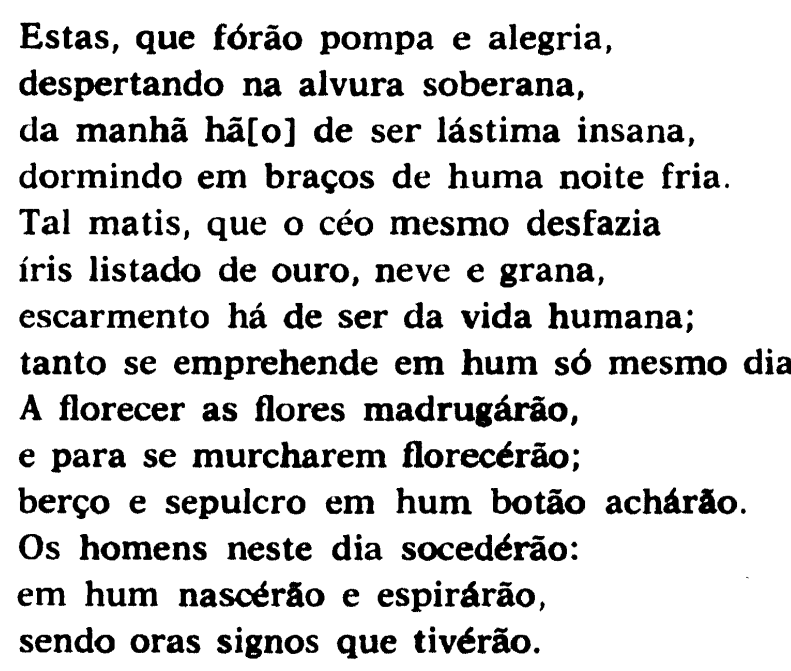

Sigue la escena en que Muley le propone la huida al Infante; el Rey los sorprende $y$, sospechando la verdad, compromete a Muley en la vigilancia personal de D. Fernando, dando lugar así a la disyuntiva amistadhonor. Calderón termina la jornada con la negativa del Infante a huir, decidido a ser "Príncipe constante / en la esclavitud de Fez» («hum Príncipe sou constante / nesta escravidão de Fez"). Poca materia ésta para llenar todo un acto; el adaptador lo soluciona con nuevas invenciones. En primer lugar, más solicitado que Calderón por el conflicto amoroso entre Muley y Fénix, insiste en él en las escenas que siguen: Fénix pide a su padre, puesto que es irrevocable su decisión de casarla con Tarudante, que sea Muley quien la acompañe a Marruecos; el Rey accede y comunica a Muley esta decisión, pero en términos tan ambiguos, que el enamorado cree ser él a quien se le concede la mano de la Princesa:

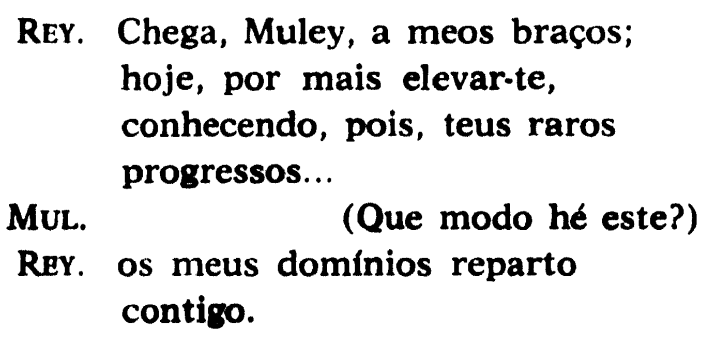


MUL.

Senhor, quanto obro,

a obediência de vassallo

hé cauza, nada me deves, que a servir sou obrigado.

REY. A teu valor muito deves,

e também a Fénis grato

te deves mostrar, que estima

o teu valor sublimado.

Mul. (Sabe ElRey o nosso affeito;

Fénis lhe disse.)

REY. Ocultando

Fénis há tempo está...

MUL. (Ah, que sou afortunado!)

REY. a glória de que tu fosses...

Fén. (Que rigor!)

MUL. (Que doce encanto!)

REY. o seu fiel companheiro.

MuL. (Que prazer tão alto!

ElRey a Fénis me entrega!, não, não posso duvidallo.)

Rey. Assim, pois, determinei...

Mul. (Ah, que não mereço tanto!)

Rey. que fosses tu da Princeza...

Mul. (O esposo feliz?, que pasmo!)

REY. O mais nobre condutor.

Mul. Condutor eu? Não alcanço.

REY. Mal me entendes as ideias ${ }^{10}$ : entre tantos meus vassallos não soube escolher quem fosse mais digno do nobre cargo de sublime condutor desta prenda que mais amo.

Para o reino de Marrocos partirás sem embaraço, conduzindo a illustre espoza de Tarudante.

Mul.

Rey. Assim Fénis mo suplica.

Mul. Fénis, senhor? (Peito ingrato!)

(II, pág. 26, cols. a-b)

Cuando, vuelto de su error, queda a solas con Fénix, la colma de reproches, juzgándola traidora a su amor; Fénix alega su obediencia al padre y pide a Muley que la mate, si duda de sus palabras. Al llegar aquí, el adaptador trasiega de nuevo escenas de un acto a otro, ahora las primeras de la jornada tercera, a partir del momento en que Fénix pide

10 Este verso está atribuido a Fénix en el texto. 
clemencia para el Infante - el traductor ha preferido distribuir la petición entre Fénix y Zara- y la recepción de dos embajadores, que no son otros que Tarudante y el rey portugués $D$. Alfonso: aquél en busca de Fénix, éste proponiendo rescatar con oro o con las armas a D. Fernando. Las armas serán las que decidan la cuestión. De nuevo, aquí, el adaptador inventa una escena de celos, resentimiento y malentendidos entre Muley, Fénix y Zara, con la que cierra el segundo acto.

Comienza el tercero con la que viene a ser la escena cuarta de la jornada tercera del texto calderoniano: D. Fernando, agotado por el trabajo y las privaciones, es la imagen de Job; aparece el Rey, acompañado de Fénix, Tarudante y Celín; el diálogo entre el Infante y el Rey está vertido con bastante fidelidad, aunque acortado -en 121 versos el romance de D. Fernando- y los acompañantes del Rey se han transformado en Zara y Turcalina. Lo que sigue a esto, excepto una escena entre Turcalina y Lourenço vestido de mora -D. Juan ofreciendo pan al Infante, desembarco de las tropas portuguesas y aparición fantasmagórica de D. Fernando ${ }^{11}-$ es, poco más o menos, igual en los dos textos. Pero la escena siguiente es ya de la responsabilidad total del adaptador: camino de Marruecos, Fénix, dispuesta a matarse antes que ser de Tarudante, declara su amor a Muley, quien reconoce la fidelidad de la Princesa, mientras Tarudante promete vengarse. El traductor, después de otra escena entre los graciosos, vuelve a Calderón, para no abandonarlo ya, salvo en una modificación final. A pesar de que el Infante ha muerto, el Rey de Fez sigue odiándolo de tal modo, que cuando D. Alfonso le propone la entrega del cuerpo de D. Fernando a cambio de Fénix y Tarudante, prisioneros suyos, el Rey se niega. Finalmente, puede más en él su amor paterno y accede al cambio. D. Alfonso regresará a Portugal con el cuerpo del Infante y los portugueses rescatados, pero antes de partir pide al Rey de Fez que case a Fénix con Muley. El adaptador atribuye, pues, al rey portugués lo que Calderón pone en boca de Tarudante. $\mathrm{Y}$ como la felicidad debe ser para todos, el adaptador casará a Zara con Tarudante y a Lourenço con Turcalina. Y así termina la comedia de "O heroico luzitano, / Príncipe constante e mártyr» 12.

Como puede verse por este resumen, a pesar de las alteraciones del texto y de la estructura dramática, las dos versiones no difieren en lo esencial. El traductor-adaptador ha respetado el doble conflicto InfanteCeuta y Fénix-Muley, aunque quizá haya dado demasiado relieve al se-

11 Calderón no indica cómo debe ser la aparición del Infante; el traductor si: «Desce huma nuvem. Abra-se a nuvem e se ve D. Fernando de militar com hum faxo na mão».

12 En Calderón: «el Católico Fernando, / Príncipe de la Fe constante». 
gundo, complicando además a Zara en el problema amoroso, tal vez pensando en el público a quien dirigía la traducción. Por supuesto que, a pesar de pasajes felices en cuanto a fidelidad traductora, se han volatilizado la mayor parte de las bellezas poéticas del original, la finura de los diálogos y la intensidad dramática del conflicto del Infante.

En lo que se refiere a la versificación, aparte la eliminación del artificio de diseminación y recolección $(I, 70-99)$ y la glosa parcial del romance de Góngora Entre los sueltos caballos ( $\mathrm{I}, 605-807)$, el traductor utiliza los mismos esquemas métricos que Calderón, añadiendo el romance heroico. La diferencia estriba en que Calderón posee un mayor dominio del verso y es más comedido y armonioso en la utilización de esos esquemas, mientras que el anónimo portugués resulta fatigosamente versátil en el uso de los mismos ${ }^{13}$.

III. La traducción de El alcalde de Zalamea, que yo sepa, desconocida hasta ahora, es un ejemplo singular de hasta donde puede llegar la arbitrariedad de un traductor-adaptador, movido por criterios personales o, una vez más, por exigencias del público al que se destina la adaptación. En primer lugar, el cambio de título. Es posible que el de El alcalde de Zalamea ${ }^{14}$ no dijese nada a ese público y sí, en cambio,

13 Compárese la métrica de las dos obras, teniendo en cuenta que, debido a las amplificaciones, cortes y otros arreglos introducidos por el adaptador, la versificación no coincide siempre, ni mucho menos, con unas mismas escenas.

Calderón I: 5 redondillas abrazadas (1-20); copla (7A-7B-7C-7B) (21-24); 36 redondillas abrazadas (25-168); romance ó-a (169-380); 24 redondillas abrazadas (381-476); silva (477-564); romance é-e (565-848); silva (849-980). Traducción (la numeración es mía): copla (8A-8B-8A-8B-8C) (1-5); silva (6-27); 8 redondillas abrazadas (28-59); copla (8A8B-8C-8B) (60-63); 7 redondillas abrazadas (64-91); 5 décimas (92-140); romance é-a (141-461); 3 décimas (462-491); 21 redondillas abrazadas (492-575); romance heroico ú-o (576-665); romance $i-a$ (666-801); 1 redondilla abrazada (802-805); 4 décimas (806-845); romance $i-a$ (846-934); romance $e-a$ (935-1023); 12 redondillas abrazadas (10241071); 10 décimas (1072-1170); 14 redondillas abrazadas (1171-1225); romance é-a (1226-1492).

Calderón II: 9 décimas (981-1070); 28 redondillas abrazadas (1071-1182); romance é-a (1183-1522); silva (1523-1601); 6 décimas (1602-1661); soneto (1662-1675); 2 décimas (1676-1695); soneto (1696-1709); romance é (1710-1907). Traducción: silva (1493-1582); 6 décimas (1583-1642); soneto (1643-1655); 2 décimas (1656-1675); romance é (1676-1854); silva (1855-1924); romance d-o (1925-2132); 10 redondillas abrazadas (2133-2172); romance heroico $\delta$-o (2173-2394).

Calderón III: 24 quintillas (1908-2028); romance é-e (2029-2216); 21 quintillas (22172311); romance ú-a (2312-2477); 6 quintillas (2478-2507); 5 décimas (2508-2557); silva (2558-2628); romance á-e (2629-2796). Traducción: 12 quintillas (2395-2455); romance ú-a (2456-2562); 5 décimas (2563-2612); romance é-o (2613-2678); silva (2679-2772); romance é-o (2773-2871); romance é-a (2872-2891); romance d-e (2892-3162).

$14 \mathrm{Ni}$ una sola vez se transcribe correctamente en la traducción el nombre de esta villa - una vez es Zalema, otra Zuleima-, quizá por yerro tipográfico. 
por alguna razón que se me escapa, el de $O$ lavrador honrado, que fue el elegido ${ }^{15}$.

Mientras que en la adaptación de El principe constante, como queda dicho, se cambiaron personajes y, entre otras cosas, se dio gran relieve a los amores de Fénix y Muley y a la intervención de los graciosos, el traductor de El alcalde de Zalamea, sea o no el mismo de la otra obra, sigue, hasta cierto momento, más de cerca el texto original, aparte amplificaciones o modificaciones circunstanciales, y se concentra estrictamente, quizá más aún que el propio Calderón, en la alevosía de D. Alvaro de Ataide, suprimiendo cualquier otro episodio que pueda distraer del conflicto central. Esto salta a la vista al repasar la relación de personajes a que ha quedado reducida la del original: D. Lopo de Figueiroa, General de Espanha; D. Alvaro de Ataide, capitão; hum Sargento; Reboledo, soldado, gracioso; Brites, sua mulher, lacaia; Pedro Crespo, lavrador, velho; João Crespo, seu filho; Izabel, sua filha; Ignês, prima de Izabel; hum Escrivão; soldados, dos quaes fálão dois ${ }^{16}$.

Notemos que la «Chispa», además de aparecer casada con Rebolledo, ha sido bautizada con el nombre de Brites, lo cual no tiene mayor importancia; pero notemos también que han desaparecido tres personajes de la lista de Calderón: el Rey Felipe II, D. Mendo y Nuño. Con la eliminación de estos dos últimos, el traductor ha suprimido unas escenas que poco o nada tienen que ver con el conflicto que se plantea en la obra, y así ésta gana en intensidad. Pero ¿y Felipe II? Felipe II, no sólo como Rey, sino, y sobre todo, como deus ex machina del drama. Aquí entramos en otro terreno sin relación con estructuras o conflictos dramáticos. La eliminación de Felipe II se explica fácilmente con poco que recordemos la historia de Portugal y lo que este Rey significó, y sigue significando, no siempre con justicia, para los portugueses: la anexión de 1580 , con la pérdida de la independencia y un largo etcétera donde cabe todo. Felipe II es un fantasma que algunos ven todavía recorriendo Portugal. Está claro que el buen público portugués del siglo xVIII no hubiera tolerado la presencia de aquel monarca, aun encarnado por un actor connacional, pisando las tablas de un teatro lisboeta, y menos aún que fuese, a mayor gloria de la monarquía española, el buen rey que evita la matanza de un

15 Comedia nova intitulada O Lavrador Honrado. Al final: «Lisboa. Na Officina de Antonio Rodrigues Galhardo Impressor da Real Meza Censoria. Anno 1784. Com licença da mesma Real Meza». 38 págs. a dos columnas.

16 Lista de personajes de El alcalde de Zalamea: El Rey Felipe Segundo; Don Lope de Figueroa; Don Alvaro de Atayde, capitán; Un sargento; soldados; Rebolledo y la "Chispa»; Pedro Crespo, labrador; Juan, hijo de Pedro Crespo; Isabel, hija de Pedro Crespo; Inés, prima de Isabel; Don Mendo; Nuño, criado; Un escribano; Villanos. 
pueblo a manos de la soldadesca y reconoce, en fin, la justicia hecha por un labrador, alcalde de ese pueblo. Esto explica también la supresión de cualquier referencia a Portugal, como las siguientes palabras de Pedro Crespo a Isabel: «Hija, el Rey, nuestro señor. / que el cielo mil años guarde, / va a Lisboa, porque en ella / solicita coronarse / como legítimo dueño» (I, 523-527) ${ }^{17}$. Mantener estos versos sería algo así como herir el honor nacional.

Queda, pues, saber cómo y quién soluciona la situación a que ha conducido el enjuiciamiento del capitán. Aquí tenemos lo inesperado de la versión portuguesa, la suprema traición del adaptador al texto calderoniano: D. Alvaro de Ataide, no sólo no es ajusticiado, sino que, arrepentido de su delito, y téngase en cuenta que su delito, aquí, no pasa del rapto de Isabel, y gracias a los reproches y amenazas de $D$. Lope de Figueroa, se arrepiente y toma como esposa a la virtuosa Isabel, contraviniendo así los prejuicios sociales que su rango le imponían, pero satisfaciendo los sentimientos de un público que descubría por entonces los encantos de la comédie larmoyante, y así, lo que en el original era un drama de honor con todas sus consecuencias, en la versión portuguesa no transgredía las fronteras de lo «pitoyable», con su cortejo de situaciones conmovedoras, ternura, virtud a prueba y desenlace feliz. Permanecía, sí, el uso abusivo de la intervención de los graciosos, demasiado arraigada todavía en los gustos de un público que parece se alimentaba preferentemente con entremeses populacheros.

Vamos a seguir ahora, como hice con El príncipe constante, el desarrollo de los dos textos, pero dando más cabida a los ejemplos, justamente por la importancia de las alteraciones introducidas por el adaptador.

La versión portuguesa comienza igual que el texto español, con la salida a escena de Rebolledo y la «Chispa», aquí Brites y transformada en su mujer. Brites es la soldadera descarada que imaginó Calderón, pero con una ordinariez que apenas apunta en la «Chispa». El traductor enzarza desde el principio al matrimonio en una discusión barriobajera, con mutuos amagos de golpes e insultos de Brites, repetidos a lo largo de la comedia, motejando a Rebolledo de marica y cobarde. Estas escenas "cómicas» entre marido y mujer son parejas a los «sabrosos» diálogos de Turcalina y Lourenço en El príncipe constante. La pareja se reconcilia y canta una jácara, incompleta y mal transcrita. En lugar del capitán, es el sargento quien comunica a los soldados que permanecerán en Zalamea varios días. El diálogo que mantienen a continuación D. Al-

17 Cito por la edición de A. Valbuena Briones, Madrid, Cátedra, 1980. 
varo y el sargento, más extenso que el del original, quizá para compensar la supresión de la escena siguiente entre D. Mendo y Nuño y la intervención de Pedro Crespo y familia, es sustancialmente el mismo en los dos textos, aunque con algunas amplificaciones; así, el comentario del capitán a los elogios que el sargento hace de Isabel, pasa de tres versos en Calderón a siete en la traducción:

¿por muy hermosa y muy vana

será más que una villana

con malas manos y pies?

$(I, 182-184)$
Pode ser mais que huma simples villaã com hum rosto chato, de cor parda, mãos groceiras e talvez que pés cambaios? Pois o estillo de falar, bronco e mal pronunciado, fará vontade de rir o mais rústico lacaio da Corte.

(I, pág. 3, col. b)

Y en una nueva réplica a los argumentos del sargento, D. Alvaro añade, con tópicos más que gastados, las cualidades de la mujer ideal:

porque en no mirando yo aseada y bien prendida una mujer, me parece que no es mujer para mí.

(id., 195-198)

\author{
Para mim não, em não vendo \\ hum semblante de alabastro, \\ bons olhos, boa boquinha \\ com beiços de cor de cravo, \\ os dentes pérolas finas, \\ fazes de rozas, dourados \\ os cabellos, a cabeça \\ com hum enfeite engraçado, \\ a cintura delicada, \\ grave[s] e honestos os passos, \\ vestido rico e da moda; \\ e depois de tudo quanto \\ te expreço, deve a mulher, \\ para ser do meu agrado, \\ além de descripção, ter \\ agradáveis predicados; \\ se lhe falta perfeição \\ das que tenho nomeado, \\ ainda sendo imperseptível, \\ já dela não faço cazo.
}

(id., págs. 3-4, cols. a-b)

Suprimidos, como queda dicho, D. Mendo y Nuño, lo que sigue es la escena entre Pedro y Juan, que, en el original, va a continuación de la de D. Mendo. El adaptador comienza a preparar la decisión que más tarde tomará Juan de alistarse en el ejército, y ya ahora le hace decir lo que, 
más avanzado el acto, le hace decir Calderón ante la presencia de D. Alvaro:

¡Qué galán y alentado!

Envidia tengo al traje de soldado.

(id., 565-566)
Que bellas que vêm as tropas!

Muito me agrado do traje

militar, e se meu pai

esta vida me deixasse

seguir, indo hoje soldado,

fora de boa vontade.

(id., págs. 45, cols. b-a)

Lo que viene a continuación es, con leves alteraciones, tendiendo siempre a la amplificación y exageración de sentimientos, igual en los dos textos: conversación entre padre e hijo, llegada del sargento con las ropas de D. Alvaro, quien viene a alojarse en casa de Pedro; éste dispone que las mujeres se retiren a un desván mientras los soldados están en el pueblo. Copio sólo las palabras, lejos del estilo de Calderón, que el traductor pone en boca de Inés, quizá para caracterizar su villanaje:

Eu de soldados

arrenego, o céo me guarde!, porque são ainda maiores maganoens que os estudantes.

(id., pág. 7, col. b)

Es sabido cómo el capitán, despertada su curiosidad por la encerrada Isabel, finge una riña con Rebolledo que lo llevará a la habitación donde se encuentra la joven. El traductor suprime la breve escena en que, a los gritos de la «Chispa», acuden Pedro y Juan. Por tanto, la fingida rina liga directamente con la escena que tiene lugar en la habitación de Isabel e Inés. A Calderón le han bastado 32 versos para que D. Alvaro exprese su encandilamiento ante la belleza de la joven y ésta lo rechace discretamente. El traductor emplea 111 versos entreverados con los comentarios del sargento. Además, el comedido galanteo del capitán en el texto español, se transforma en un vendaval apasionado en el portugués:

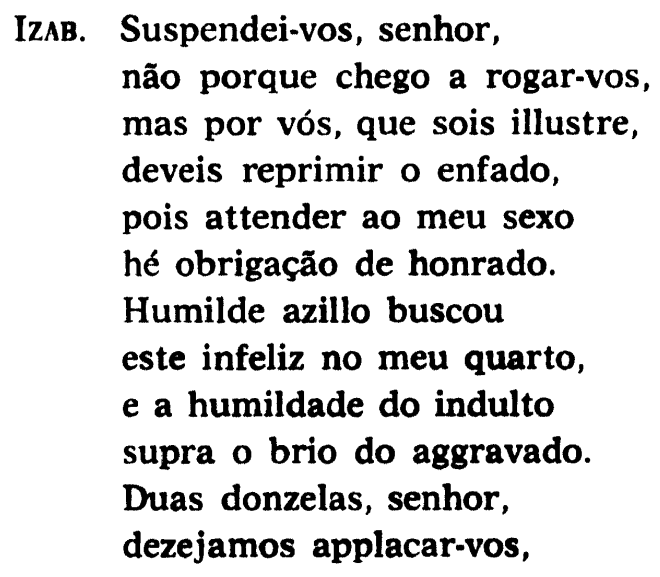


e para mais dignamente vossa attenção alcançarmos, nos basta o sermos mulheres e a vós o serdes fidalgo.

CaP. (Que vejo!, que ouço!, oh céos, que produzisse este campo formozura tão discreta! Eu me sinto perturbado! ) Com a vida esse atrevido me pagaria hum aggravo, se tanto lhe não valera da vossa caza o sagrado; pois a vossa formozura, vossos doces predicados suspendérão bravas feras, quanto mais peitos humanos, por vós lhe perdoo a offensa que me fez.

SarG. (Ai meus pecados, que já cahio o nugento como hum patinho no laço!)

IzAB. A mercê vos gratifico e a lizonja vos estranho.

CAP. Não hé lizonja... (Ai sargento, que a rapariga hé hum pasmo!)

SARG. (Qual pasmo!, tem maons groceiras, hé parda e tem o rosto chato!)

CAP. (Oh, que rara gentileza!)

SARG. (Olhe, tem os pés cambaios!)

CAP. (Ardo de amores!)

(E os burros são todos do mesmo tamanho!)

CAP. (Sim, amigo, ben te entendo: já de mim estás vingado.)

IGN. (Prima, tens de aturar aqui estes espantalhos muito tempo?)

IzAB. (Na verdade que já de os ouvir me enfado.)

ReB. Senhora, posso já hir-me?

IGN. Hum cavalheiro bizarro não falta à sua promessa.

CAP. Sim, já ficas perdoado. A esta excelça deidade, onde aliança está jurando, com o primor da belleza, da sabedoria o raro, agradece o estares vivo. E vós, ídolo adorado, 
adverti que não hé justo

que este rostro soberano

obre em mim hum homicídio

quando outro prohibe ao meu braço.

IzaB. Cavalheiro, de cortez

hides passando a affectado;

reflecti milhor que sou

camponeza e vós fidalgo;

por amante e lizongeiro

não queirais ver mal logrado

os méritos que possuis

por attenciozo e sábio.

Sincera vos suppliquei

que deixasseis o soldado;

deixaste-o, mercê que devo

reverente confessar-vos;

mas não busqueis que vos pague

a dívida o meu recato;

não amante cavalheiro

vos estimo; retirai-vos,

pois será grande desgraça

que neste improvizo acazo

meu inocente decoro

sinta a pena de culpado.

CAP. Eu sou do vosso decoro

o defensor mais exacto,

e quem quizesse offende-lo

me faria a mim aggravo.

Vós sois a minha senhora.

SARG. (Senhor, estais insensato?

Minha senhora chamais

a huma villaã?)

CAP.

(Estou vário.)

SARG. (Basta o nome de villaã

para que lhe tenha asco.)

IzaB. Se quereis que vos deva outra

mercê maior, auzentai-vos,

pois temo que meu pai venha

encontrar-vos neste quarto,

que hé do crédito zelloso

como lavrador honrado.

CAP. Meu bem, minha doce prenda, eu não me atrevo a deixar-vos:

morrer me sinto de amor.

IGN. (Este homem hé o diabo!)

Iz.AB. (Ai prima, estou assustada!)

CAP. As vossas plantas prostrado

deixai que essa mão de neve...

(id., págs. 9-11, cols. b, a-b, a) 
Y en este preciso momento, cuando el capitán «quer beijar-lhe a mão de joelhos", irrumpen en escena Pedro y Juan. El resto, hasta el final del acto, no se desvía del original más que en alguna amplificación sin importancia. Sí quiero hacer notar que el adaptador continúa subrayando el carácter arrogante e insolente de D. Alvaro.

Copio a continuación parte del popular diálogo entre Pedro Crespo y D. Lope de Figueroa, con el que termina el primer acto; así se podrá ver mejor cómo el traductor maneja el texto calderoniano:

Don Lopf. A quien tocara ni aun al soldado menor sólo un pelo de la ropa, por vida del cielo, yo le ahorcara.

PEdRo. A quien se atreviera a un átomo de mi honor, por vida también del cielo, que también le ahorcara yo.

DON LOPE. ¿Sabéis que estáis obligado a sufrir, por ser quien sois, estas cargas?

Pedro. Con mi hacienda, pero con mi fama no.

Al Rey la hacienda y la vida se ha de dar; pero el honor es patrimonio del alma, y el alma sólo es de Dios.

(id., 861-876)
Lop. E qualquer vil, temerário, que o atrevimento tenha de me tocar no vestido do menor soldado, entenda que logo, logo o enforco.

PrD. E quem tiver a afoiteza de offender na menor parte a minha honra, tambén creia que os enforco logo, logo.

Lop. (Responde-me ao pé da letra o vilão! Gosto de ouví-lo!) Sabei, pois, que ElRey ordena que estais, por serdes humilde, obrigado a com paciencia mil incómodos sofrer com militares.

PED. Fazenda, caza, vida e tudo a ElRey se deve dar com franqueza, menos a honra, porque hé património d'alma bella, e a alma hé daquelle Rei que a todos os reis governa.

(id., págs. 13-14, cols. b y a)

El segundo acto comienza en una "praça com o corpo da guarda», y en ella D. Alvaro y el sargento. El traductor, quizá con más lógica que Calderón, suprime aquí a Rebolledo - no olvidemos que ha dejado en evidencia a D. Alvaro al contar a D. Lope la verdad de la riña-, y es el sargento quien le propone dar serenata a Isabel. Después - «vista de jardín»- asistimos a la cena de D. Lope. El traductor continúa ceñido al original, aunque lo modifica cuando, por lo que sea, no está de acuerdo con él, y así lo abandona, sin duda por incapacidad de trasladar la imagen al portugués, al elevarse el lenguaje a un plano metafórico: 
PEDRo. Un pedazo es de jardín do mi hija se divierte. Sentaos, que el viento suave, que en las blandas hojas suena de estas parras y estas copas, mil cláusulas lisonjeras hace al compás de esta fuente, cítara de plata y perlas, porque son en trastes de oro las guijas templadas cuerdas ${ }^{18}$. Perdonad, si de instrumentos solos la música suena, de músicos que deleiten sin voces que os entretengan; que como músicos son los pájaros que gorjean, no quieren cantar de noche, ni yo puedo hacerles fuerza. Sentaos, pues, y divertid esa continua dolencia.
Ped. Hum pedaço hé de pásseio sem culto ou delicadeza, onde a minha pobre filha se diverte, e para ella, que nunca vio os da Corte, cheio de magnificência hé este simples retiro, huma estancia de Amalteia. Sentai-vos, que o vento suave que soa nas folhas tenras, faz com o murmurio da fonte huma consonancia bella, e talvez que vos divirta essa contínua doença.

(II, pág. 17, col. a)

(II, 1085-1104)

Poco después, el adaptador introduce - ¿por más lógico?- un pasaje que no existe en Calderón; me refiero al ingreso de Juan en la tropa de D. Lope. En Calderón, esto no ocurre hasta muy avanzada la jornada segunda, cuando, sin más antecedente que unas palabras de Juan comentando otras de D. Lope ${ }^{19}$, éste agradece a Pedro el permiso para que su hijo sea soldado. En el texto portugués, al elogiar Pedro el brío de Juan, D. Lope le dice:

18 La imagen procede de Góngora, n..$^{390}$, ed. Millé:

Sobre trastes de guijas cuerdas mueve de plata

Pisuerga, hecho citara doliente; y en robustas clavijas de álamos, las ata

hasta Simancas, que le da su puente...

19 D. Lope dice «que es estrecha / religión la de un soldado», y

JuAN. Con todo eso es linda vida.

DON LOPE. ¿Fuérades con gusto a ella?

JuAN. Si, sefior, como llevara por amparo a vuecelencia.

(II, 1221-1224) 
Que não hé bem que ElRey perca hum tão bom soldado, Dai-mo.

PeD. Senhor, desta caza inteira sois, e podeis, como vossa, dispor livremente della.

Lop. Ah Pedro, e com que glória verei-lo em differente esfera 20 com distinção brevemente!

PED. Vê-lo-ei, sim, com a mesma com que vo-lo entrego já, que em hir na vossa assistência a fazê-lo venturozo principia a sua estrella.

(id., pág. 17, col. b)

Y poco después, cuando entra Juan, el padre le comunica la noticia:

PED. Prosta-te aos pés do senhor

D. Lope e a mão lhe beija; para servires a ElRey, filho, consigo te leva.

JUAN. Ah senhor, vós prevenistes os meus dezejos! Sempre essa foi a minha inclinação, e quando por esta terra via passarem soldados, me fazia grande inveja; e se a meu pai não tivesse tão respeitoza obediência, lhe fugira, por seguir as militares bandeiras.

LoP. Serás hum grande soldado; o dezejo e a idade bella, meu exemplo e proteç̧åo te fará distincto.

(id., pág. 18, cols. a-b)

En fin, unida a la cena están la serenata de los soldados y la rifia con éstos, etc., hasta el final del acto, con las alteraciones que señalo. Por ejemplo, el traductor sitúa los consejos de Pedro a su hijo antes de la despedida de D. Lope; Calderón, después; el rapto de Isabel no se hace a la puerta de la casa, sino en un lugar del campo, por donde caminan padre e hija, y en la escena última - voces de Isabel y Pedro, dentro, y soliloquio de Juan-, éste rescata a Isabel de las manos de D. Alvaro

20 Corrijo el texto, "vereis en differente esfera», sin sentido claro.

LXIII, $1.0-2 .^{\circ}-8$ 
y un soldado, y mientras lucha y hiere al capitán entre bastidores, Isabel, atemorizada, se aleja, porque, dice:

Fujo do irmão, pois receio

que o zelo da honra e fama

em minha inocente vida

também empregue a vingança.

(id., pág. 27, col. b)

Notemos que Isabel se declara inocente, y lo es de hecho y derecho, no sólo por no tener culpa en el rapto, sino porque D. Alvaro no ha llegado a consumar sus planes.

Quiero señalar también la insistencia del traductor en caracterizar a D. Alvaro como un individuo despreciable, que sí lo es, recargando las tintas en sus acciones y palabras, mostrándolo cruel, grosero y valentón. Donde Calderón pone "hermosísima villana» o "hermosa homicida», el traductor le hace decir "vil lavradora» $\mathrm{y}$ "traidora»; donde Calderón dice "amor», el traductor pone "vingança» $y$ "furor vingativo»; D. Alvaro está dispuesto a matar "a família toda / desta villãa», empezando por Pedro, "velho indigno» ${ }^{21}, y$, en fin:

Já que desprezaste ingrata
as minhas doces lizonjas,
tremerás da tirannia
que me dita a paixão louca.

(id., pág. 23, col. a)

Calderón comienza la tercera jornada con el encuentro de padre e hija en el monte; Isabel relata lo ocurrido, y al regresar al pueblo, les sale al encuentro un escribano, comunicando a Pedro que ha sido elegido alcalde y la llegada del capitán herido. El traductor reduce la escena inicial, acortando implacablemente las dos intervenciones de Isabel: de 66 a 6 versos y de 174 a 82 . Eso sí, de sus palabras se desprende claramente que el capitán no logró sus propósitos:

fiquei de manchas indignas, mas tremo dos maus conceitos, porque, nas mordazes línguas, como delicto provado o erro aparente periga.

(III, pág. 28, col. b)

21 El «Dale muerte», que Calderón pone en boca de Rebolledo, el traductor lo pone en la del capitán: «matai o velho». 
En la escena siguiente, Calderón presenta al capitán en Zalamea acompañado de sus compinches; después, la gran escena entre D. Alvaro y Pedro Crespo - arrogancia y súplicas frente a frente- y la orden de que todos sean juzgados; llegada de Juan, intentos de matar a Isabel para vengar el honor de la familia, y oportuna aparición de Pedro.

Como de costumbre, el traductor amplifica, tal la escena entre $D$. Alvaro y los suyos y la de los intentos de Juan para vengar su honor, intercalada a continuación de aquélla. Sigue el diálogo entre Pedro y el capitán, con las mismas características y resultados que en el original. Isabel anuncia la llegada de D. Lope -en el original entra sin que nadie lo anuncie-, y ya sabemos cómo resuelve Calderón el conflicto: D. Lope y Pedro mantienen la discusión sobre las jurisdicciones civil y militar, y cuando D. Lope, enfurecido, ordena el asalto a la cárcel, donde supone que está preso el capitán, llega Felipe II providencialmente, Pedro le comunica el ajusticiamiento de D. Alvaro, y el Rey da por bien concluido el asunto. En fin, la pobre Isabel ingresará en un convento y Juan se incorpora a la tropa.

Hemos llegado al desenlace del drama y, como ya adelanté, el adaptador se permite la máxima libertad para resolver el problema familiar de Pedro Crespo. La escena con D. Lope es, en cierta medida, más breve y carece del nervio y la fuerza del diálogo original, pero sí introduce la nota patética en el relato que hace Pedro de lo sucedido, al punto que D. Lope se indigna y conmueve cuando Isabel se echa a sus pies pidiendo amparo. Estamos en plena comedia lacrimosa. Lo que parece exagerado es que no habiendo ocurrido nada irreparable se arme semejante tragedia y Pedro diga, con palabras que Calderón sitúa más adelante, que Isabel tendrá digno esposo en la clausura de un convento. El adaptador ha tenido sin duda en cuenta el reproche que D. Lope hace a Pedro, ya al final de la obra, cuando le pregunta: « ¿No fuera mejor hablarme, / dando el preso, y remediar / el honor de vuestra hija?» (2740-2742). Pedro e Isabel, además, han hablado cuando D. Alvaro todavía no ha sido ajusticiado, hay tiempo, pues, para remediar el honor, o la fama, con una componenda que ponga feliz término a lo que va a desembocar en drama. Eliminado Felipe II, el deus ex machina, o, mejor, el componedor, y además casamentero, será $D$. Lope; él mantiene con el capitán un diálogo paralelo al mantenido anteriormente por Pedro y D. Alvaro, pero ahora de general a capitán. D. Alvaro teme el castigo que pueda imponerle D. Lope ${ }^{22}$, quien lo recrimina duramente:

22 Licencia Creative Commons 3.0 España (by-nc)
CAP. Estrella contraria!

D. Lopo me arruinará pelo que estima a esta caza! 
Faltar ao seu general, huma donzella roubada, aos soldados induzir para homicídios, estranha acção de hum homem de bem que offende as leis do monarcha!

(id., pág. 37, col. a)

D. Alvaro intenta aún disculparse, reconoce su delito; está dispuesto a pagarlo, vil todavía, con dinero:

Confeço que fui tiranno
e que levado da infámia
difamei a huma donzella
que o vosso respeito ampara,
e se parte dos meus bens
satisfazem esta falta,
para dote os offereço.

No basta, responde D. Lope, es necesario algo más importante; D. Alvaro comprende que el general insinúa boda; él aceptaría, pero...:

$$
\begin{aligned}
& \text { LoP. Que vos embaraça? } \\
& \text { CAP. Embaraça-me a nobreza } \\
& \text { da minha distincta caza. } \\
& \text { Lop. Não devo obrigar-vos a essa } \\
& \text { união, que ao céo hé grata, } \\
& \text { porém só vos lembro que } \\
& \text { muitas famílias de Espanha, } \\
& \text { que não só convosco ródão, } \\
& \text { mas comigo ainda iguálão, } \\
& \text { nascérao de lavradores, } \\
& \text { e se as idades passadas } \\
& \text { recordamos, muitos reis } \\
& \text { os lavradores gerárão. }
\end{aligned}
$$

Estos argumentos, aireados desde el siglo xvi por moralistas y políticos, convencen de inmediato a D. Alvaro. El general llama, gozoso, a la familia Crespo; comunica la noticia; Isabel parece resistirse a creer tanta dicha, y pide una merced a D. Alvaro:

Que me deixeis num convento hir viver; da repugnância que aos vossos olhos fará huma espoza villã, grata vos quero exemir, senhor, 
pois o ver já restaurada

a minha boa opinião,

para fortuna me basta.

(id., col. b)

Y D. Alvaro, muy cortesano - ¡cuán rápidamente ha cambiado de condición! - :

Como sois já minha espoza, vos amo como fidalga.

Y el drama termina como comedia, con perdón general y boda en puertas.

Como en el caso de El príncipe constante, las conclusiones a que se puede llegar tras este análisis son poco más o menos idénticas, excepto en la versificación, fluida, pero pobre y monótona en $O$ lavrador honrado, frente a la variedad de El alcalde de Zalamea: nótese que el traductor, salvo tres coplas irregulares, ha utilizado exclusivamente el romance ${ }^{23}$.

\section{José AREs MONTES}

23 Calderón I: 24 redondillas abrazadas (1-100); coplas (8A-8A-8B-8B-8C-8D-8C-8D9-E-8D-10F-8D) (101-112); 24 redondillas abrazadas (113-212); romance d-e (213-556); silva (557-680); romance é (681-894). Traducción (la numeración es mía): romance deo (1-92); copla (10A-9A-9A-8A-8B-11A) (93-98); romance á-o (99-251); romance a-e (252-567); romance á-o (568-757); romance é-a (758-1030).

Calderón II: romance é-a (895-1230); copla (7A-5B-7C-8B) (1231-1233); romance é-a (1234-1248); 9 redondillas abrazadas (1285-1320); romance $u$-e (1321-1340); 14 redondillas abrazadas (1341-1396); 21 quintillas (1397-1501); 1 redondilla abrazada (1502-1505); romance i-o (1506-1787). Traducción: romance é-a (1031-1459); copla (7A-5B-7A-8C-5B) (1460-1464); romance é-a (1465-1531); romance o-a (1532-1543); copla (8A-8B-8B-8A-6C6D-6D-6A) (1544-1551); romance $\delta$-a (1552-1691); romance i-o (1692-2004); romance d-a (2005-2030).

Calderón III: romance i-a (1788-2135); 14 redondillas abrazadas (2136-2191); romance é-o (2192-2305); 80 redondillas abrazadas (2306-2625); romance $d$ (2626-2767). Traducción: romance i-a (2031-2307); romance é-o (2308-2596); romance d-a (2597-2813). 